\title{
Deployment of e-services based contextual smart agro system using internet of things
}

\author{
Abdus Sattar, Yeasin Arafat Shampod, Md. Tanjid Ahmed, Nasrin Akter, Arif Mahmud \\ Department of Computer Science and Engineering, Daffodil International University, Address, Dhaka, Bangladesh
}

\begin{tabular}{l}
\hline \hline Article Info \\
\hline Article history: \\
Received Jun 16, 2021 \\
Revised Sep 7, 2021 \\
Accepted Dec 14, 2021 \\
\hline
\end{tabular}

\section{Keywords:}

E-service

ICT

ICTization

IoT

Smart agro system

\begin{abstract}
Climate change's effects are becoming more apparent, and farmers are bearing the brunt of the consequences. As a result, by 2050, food production is expected to decline by $18 \%$. Therefore, the study's goal is to develop effective and well-organized roadmap for context-based smart agricultural systems using a pre-determined ICT framework. Following that, this study offers a four-level conceptual framework for an e-services-based smart agro system utilizing internet of things (IoT). Here, each level optimizes the IoT infrastructure to accept e-services based on contextual information supplied by the e-services. Furthermore, the proposed ICTization process intends to broaden the role of ICT technology development. Besides, the system's views decrease misunderstandings about technology, growth, and connectivity while also enhancing raw data, administration, and service synchronization. Farmers, agricultural officers, and network operators, for example, are all included in the proposed roadmap, which includes omnipresent farm treatment services. Precision farming, on the other hand, need new knowledge and innovation in order to achieve an integrated and comprehensive approach to technology.
\end{abstract}

This is an open access article under the CC BY-SA license.

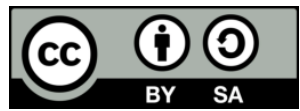

\section{Corresponding Author:}

Abdus Sattar

Department of Computer Science and Engineering

Daffodil International University, Dhaka, Bangladesh

Email: abdus.cse@diu.edu.bd

\section{INTRODUCTION}

Agriculture accounts for $19.6 \%$ of total national output and employs $63 \%$ of Bangladesh's population. According to the World Bank, Bangladesh has only $61.2 \%$ of arable land (up from $68.3 \%$ in 1980) since the population growth rate is reducing the available arable land consistently. In Bangladesh, rice, jute, and tea are the key products, and these crops have dominated agricultural exports for decades. Although, mostly brown rice is consumed domestically, jute and tea are the biggest export payers. Farmers also raise sugarcane, tobacco, cotton, and a variety of fruits and vegetables (sweet potatoes, bananas, pineapples, and so on) for the home market. However, there is a water issue; available freshwater is being increasingly contaminated by the population of humans and animals, and the population is growing at an unprecedented rate. A competent and intelligent agricultural system that can assist farmers in making wise use of water levels while also addressing other issues such as unrequested animal intrusion into fields. The system includes microcontrollers and measures such as pressure, temperature, moisture content, and motion. Besides, the system employs wireless links to link sensors, microcontrollers etc. with mobile application.

In fact, the proposed model also includes a mobile application that enables the client to manage watering power. On the contrary, the smart agriculture project will combine the internet of things (IoT), cloud computing, and a wireless sensor network in this article to assist farmers in scheduling their farm's 
irrigation schedule through an agricultural profile that can be changed according to their needs. To optimize the usage of water for the agricultural field, an algorithmic watering system is built based on user feedback. The suggested system would feature a decentralized wireless communication system installed in the root zone of the plant to monitor soil moisture and temperature.

In this model, a gateway unit manages sensor data, activates sensors, and transfers information to a web service. To measure water volumes, temperature and soil moisture limit values was defined and put into a microcontroller-based gateway. For healthy crop development, adequate irrigation and fertilization planning are critical. Importantly, moistness, sunlight, wind speed, passive infrared detector, seed surveillance, and heat are all elements that influence the number of water crops required to meet specified environmental conditions. Further, the field-based climate data gathered and inferred, as well as web weather data directories, are employed to create a few effective farming judgments. If the weather is warm, dry, hot, and windy, crops require a lot of water, however, if the weather is cold, humid, and foggy crops require less water.

This suggested model, which expands the ICT infrastructure promotion endeavour, is built on a context-aware conceptual framework and an ICTization process approach. From a commercial standpoint, this effort would aid in the development of a model for categorizing and estimating the range of infrastructure components used in information and communication technologies to achieve exact tactical engagement. Nevertheless, this study gives a comprehensive framework for increasing agricultural output and improving crop quality. The potential use of IoT in agriculture is to provide farmers with decisionmaking tools and automation technologies that seamlessly integrate product information and services to increase productivity, performance, and benefit.

Notably, Bangladeshi farmers are currently confronting several problems, as agriculture's importance to humankind rises. Besides, the impact of climate change is becoming increasingly obvious, and producers are the ones who are suffering the most. Therefore, it is anticipated that food output would drop by $18 \%$ by 2050 . In contrast, rapid population expansion raises food consumption, but urbanization reduces arable terrain. Furthermore, there is fierce rivalry among farmers to save expenses and differentiate themselves. All of these factors have prompted us to create a smart agricultural system for Bangladeshi farmers and the agriculture business.

We've listed some study goals, which may be explained by the assumptions we've proposed in the rest of the study:

- For context-based smart agricultural systems, functional and organized advice must be built over a predetermined ICT framework.

- There should be no borders around the system; users should be able to access services from anywhere at any time.

- The platform must be accessible; customers should have unrestricted access to and usage of the resources.

- In the suggested approach, the positions of various entities or stakeholders are defined and divided

- By providing prompt support and services, the model should be able to attain a degree of satisfaction.

Agricultural research is being developed in a variety of methods to increase the quality and quantity of agricultural product productivity. Here, scientists were on hand to study soil features, weather conditions, and crop scouting for a variety of projects. They have found that low-cost and low-power are the critical components of a usable and acceptable IoT network for farmers. Following the approach, Heble et al. [1] describes a smart agricultural model that employs a low-cost, low-power IoT network to monitor soil moisture using in-house designed sensors that consume less power and have an average lifespan of $83 \%$ at a lower cost. Besides, farmers have adopted various smart agricultural practices as a result of global climate change and inconsistency in rainfall over the previous decade. Another study [2] presented a remote monitoring system that collects farm data in real-time via the internet and wireless connection, agricultural services more accessible. It is also noticed that farmers are focused on smart agriculture as the world's population grows and agricultural land becomes scarce.

The determination of which ISA model indicators are more important or expressive for a rural property's sustainability, as well as a discussion of the amount of data that ISA required and the possibility of reducing the input. A data science-based information system for agroecosystem sustainability management that enables to using the ISA methodology, gather, organize, and validate data on agroecosystem sustainability. The first simulation involves doing feature selection experiments on various cuts of the dataset to replicate the calculation of the ISA sustainability index with a less amount of data for each property [3]. The PVA/SCN ionic polymer fabrication method and silver electrode layers were pasted on both surfaces of the PVA/SCN ionic polymer to develop sensors with a paintbrush and measured dielectric data with the electric field and sensing electrical signals with bending strain. According to reports, silver paste has excellent electrical conductivity and chemical stability [4].

A prolific agricultural pest known as fall armyworm has recently invaded Africa and Asia. FAW could cost Africa up to $\$ 16$ billion in crop losses each year. Use of chemical pesticides could undermine pest 
control through natural enemies to review the literature on agroecological approaches to control FAW. Smallholder farmers can benefit from proven low-cost agro ecological approaches [5]. Setting up an admonitory framework that's area particular and responsive to person famers needs includes intuitive between different on-screen characters to the setting of take-up/ take after up of advisories by the agriculturists, there were contrasts depending on the sort of edit developed. In common, agriculturists take after advisories in case of tall esteem crops as compared to staple nourishment crops for application of Diammonium phosphate and complex fertilizers, micronutrients, pesticides, weedicides. Climate advisories had great take-up independent of sort of trim [6].

This inquiry about pointed to extend the control framework of a stepper engine to imitate the movement of shade for greenhouses. The control flag was transmitted through wireless communication utilizing an android application that can be installed on a smartphone. Another strategy of input was through the onboard buttons that are display on the microcontroller board of following encounter (NXP) semiconductors. Due to the increasing demand for developing crops year-round, there is a great potential for improving structural and controlling applications for nurseries, which, on the other hand, will be extremely valuable in cost-effectively expanding self-employed enterprises [7]. Clisagri, a new climate service instrument for the agriculture sector, has been developed to the danger of unfavorable weather events during crop growth is modeled. The use of a dynamic phenological model allows for the identification of growth stages that are particularly sensitive. Crop cycle length can be optimized by optimizing variety selection [8]. Developing a software based on Windows as something of an input element, the condition of the soil at a given time in terms of nutrient content to developed a database and software for its management and calculation of nutrient requirements based on measurements or estimates of existing nutrients and agrotechnical requirements for the crop. There is a dialog box that is interactive and guides the user to enter the correct values and the error messages are displayed if the values have not been entered correctly. Farmers will be able to make decisions about crop plans, optimal nutrient use, and cost reduction with the help of this program [9].

It has been widely used in agriculture to determine the energy efficiency of different parts of the agricultural sector by using energy audit analysis. When it came to estimating tobacco production's energy output, human effort was found to be the most important factor. When it came to projecting tobacco production's energy output, chemical fertilizers were shown to be the least accurate method. Briefly considered as the most suitable structures for ANN models to anticipate the seed and grain corn yields to tobacco production's energy output might be predicted with good accuracy using the selected model [10]. The implementation methodology to selecting a control system, the first step is to identify the device's purpose and future potential. Unlike industrial control systems, the idea of mobile machine control systems differs \& each peripheral will communicate via the CAN bus, it is not essential to create an infrastructure for compatibility. When it comes to remote access, CAN bus should be used as the primary communication method [11]. It's crucial for industry 4.0 to digitize data from control systems and other sources that may be used for the smart city idea. An IoT-based irrigation approach [12] with restricted water availability has been presented. Temperature and humidity are monitored by sensors and the model reacts accordingly by providing the necessary amount of water. This initiative aids farmers in properly irrigating their property through the use of drip irrigation. Using a soil moisture-based automated watering system and they used to GSM SIM900 module with 6 pins is used for hardware connections with Arduino Nano. It employs AT instructions for wireless communication and is extremely small and lightweight to this model is used to capture real-time data on the Green Gram crop across a 50cms region.

It came up with a way to test closed agricultural greenhouses using a fogging system designed to utilize the least amount of water and electricity. On the other hand, the cooling effectiveness of water at room temperature was compared to that of chilled water. To show the results, the system reads the display value from the experiment and transmits it to the ESP8266 board. When the data is received, the ESP8266 board transmits it to the Blynk application. In terms of the water discharge estimates for various vegetables, fruits, and plants, there is space for improvement in the system [13]. It's estimated that there are seven mobile applications, each with its own each application has its own unique set of capabilities. All of these apps are designed to assist farmers in increasing the yield of their crop. Agriplex India's first priority is to provide a farmer-friendly application that provides a wide selection of agricultural input items from top manufacturers. Also using this module, K-means clustering is utilized as the data mining technique. There is a vector quantization approach called K-means clustering that uses the sensor data as input. That's because it's a great mix of IoT, data it also encourages low-income farmers to adopt climate-smart farming practices [14]. Measurements of power usage are described in this article. Other equipment was also observed on the site, allowing the data to be used to determine which machines are the most vital in a plant. That was using the wireless local energy meters system and it's offered by LEM, a global leader in current transducers manufactures by power consumption [15]. Talk about the obstacles of documenting the smallholder farmer's transactions and building the ecosystem for employing blockchain technology in the smart agro based 
technology. In the proposed approach, farmers would sell their crops directly to merchants, dealers, government-run supermarkets, and customers in the immediate vicinity of their supply chain of agro commodities. Government regulatory bodies will function as the auction's chief in this very secretive procedure and described in this article is a Web application that allows government entities to advertise and decide on auctions [16], [17].

Researchers in this study focused on real-time data from sensors, which was a major emphasis Presented a system using two Arduino boards, one for reading data from a solar panel and the other for rotating the solar panel based on the brightness of the light. Also using two components in this machinelearning algorithm: a dependent factor and an independent factor. However, this solar radiation or intensity may be intelligently used to increase crop production and yield. A feasibility analysis of planting a crop at an unknown place can be readily done using our suggested method because it's portable and based on the scientific needs of the crop [18], [19]. As part of this paper, the optimal solution was provided, as well as the potential of using the cyber-physical (CPS). For example, a wireless sensor network in the field may be used to identify rodent movements and capture, store, and display the data. As a result, their attention is drawn to techniques for managing the various subsystems of a management system to employed in order to determine if a communication network's an input argument [20], [21]. Dijkstra's algorithm and radians method were coupled in this work with a mobile-based application for the route guiding system, resulting in the mobile application used was above the laptop or personal computer. With the help of the Google APIs server, they integrated the Dijkstra algorithm with dynamic maps based on latitude and longitude in order to improve the navigation radius, they utilized radians on dynamic coordinates to optimize the distance. The original Dijkstra method is compared to the updated Dijkstra algorithm in the Android navigation system [22], [23]. Machines and people are constantly blurring and redefining the division of labour in production, assembly, distribution, and transportation. From an innovation economy viewpoint, this study sheds light on how drones may be used in agriculture as a sustainable tool and as a labour replacement in an area where automation is low compared to other industries. Physical infrastructure and the proper policy-institutionallegal frameworks are required for governments to encourage productive and inclusive usage of drones in the agriculture industry [24], [25].

Recent those smart agro systems are developed these are mainly focus on resourceful operations of agriculture officers, farmer, and network operators to constant monitoring management. These improvements have been made possible by the active use of ICT by farmers and agricultural officials. The justification for using ICT for socio-economic development as well as modern agricultural development. These e-servicebased relevant smart agro system services must be controlled and by the Government. It is more essential to focus user needs whenever develop such kind of e-services based system. Furthermore, the services demanded must be affordable and user-friendly. Any delay in receiving the services might cause tremendous loss for farmers which can't be recovered.

However, the e-services based contextual smart agro system, we proposed which can be contribute to more efficient e-services based agro system with reduces the expenses and possible to improve farmer's satisfaction and enhance farmer's outcomes. Based on our study to provide the quality of services, combination and clarifications are merged several hypotheses for this research specified as:

H1: Insufficiency of agricultural skilled and professionals have adverse impression on traditional agro management system.

H2: Precision farming and knowledge and innovation on agro systems can impact system development.

H3: Agricultural products expenses growths with ages reduce the risk to receive services from current system.

H4: Occasional agro system requirements for elderly people have positive impact on system execution.

H5: New strategy and agricultural technological facilities have an optimistic impression on system installation.

H6: The impact of human participation has a positive impact on access to benefits outside the ICT framework.

H7: Ease of use have a positive effect on the efficiency and usability of the system.

H8: Consistency and relative advantages positively affect system adoption.

\section{MATERIALS AND METHOD}

The major tasks of this framework are to investigate and decide on the intelligent actions of these smart gadgets by developing various forms of interconnection between them. This new architecture would aid in the optimization of IoT technology since it can give services based on background data while preserving the existing infrastructure. Consequently, the successful collaboration of these different devices and methods might lead to future environmental computing that maximizes cloud computing usage.

\subsection{Background of the conceptual framework}

The total network system will be divided into a four-layer system for collecting context-based raw data from the IoT which is depicted in Figure 1. These four layers form a broad framework that does not alter 
the existing network architecture but establishes a network virtualization interface between services and entities.

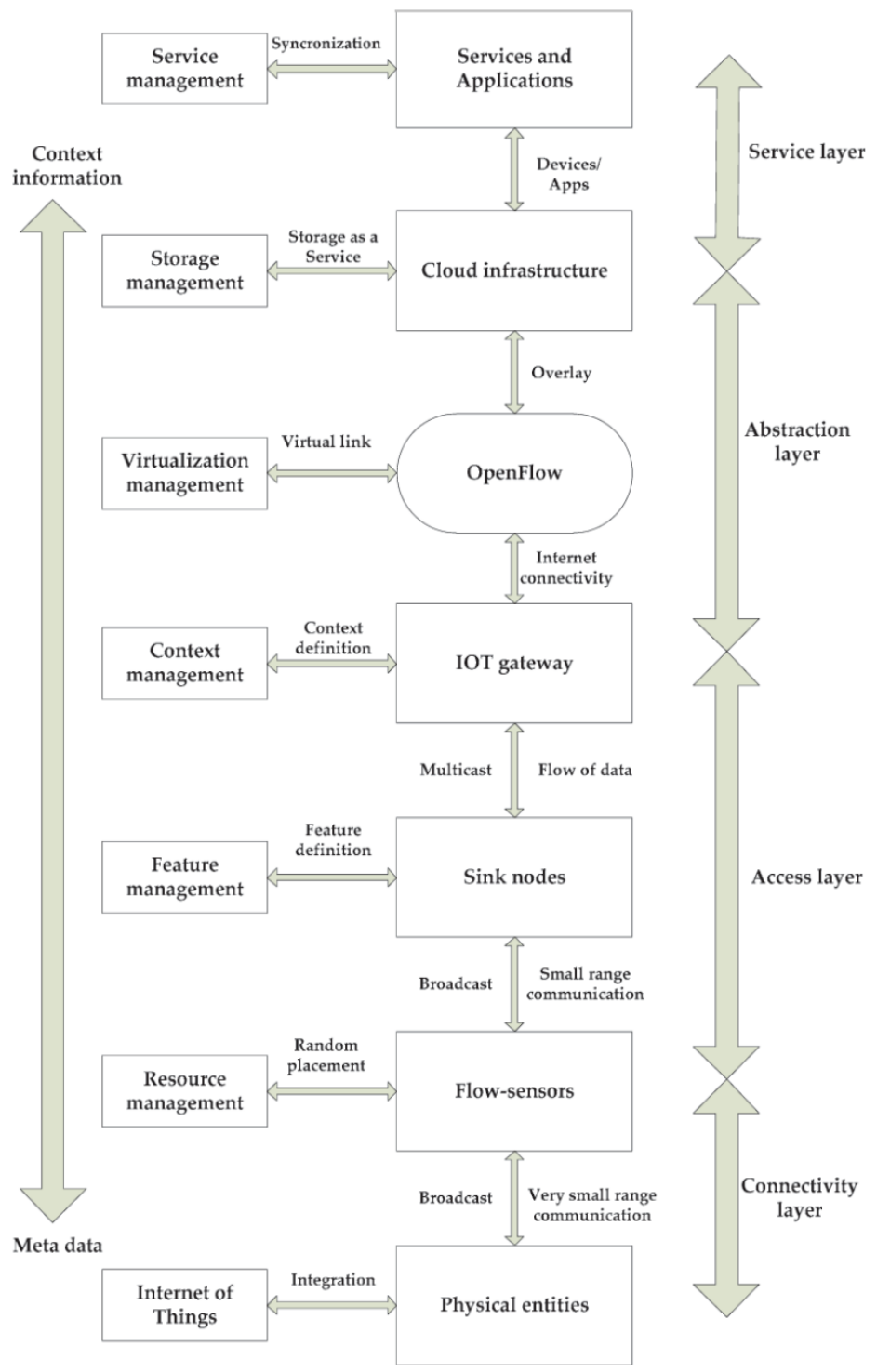

Figure 1. Background of the conceptual framework

\subsubsection{Connectivity layer}

This layer's physical devices are linked together in terms of structure and connection. Notably, the internet's future depends in large part on merging these common challenges into a system that is accessible from everywhere, near at hand, and personally identifiable and controlled. Besides, inventory management examines the physical allocated efficiency of all underlying infrastructure devices and networks. These tools have extremely low resources, and with a small overhead, the resources guarantee that they can be used in their full potential. Moreover, it allows information to be exchanged and sent across numerous networks or domains within a single network. In contrast, RFID tags may be used as an example of communication devices that are very short and compact enough to fit everywhere. It also can take electricity from the sun, eliminating the need for a battery or external power source. Afterward, sensor combines a large variety of RFID tags with a small number of smart devices enabling multi-hop data transfer to reach the IoT gateway [26]-[28]. 


\subsubsection{Access layer}

An IoT gateway will be used to transport raw data from short-range devices to the internet. This layer is in charge of designing topology, launching the network, and establishing the domain. In addition, communication configuration, intra-inter domain interaction, planning, flow-sensor transmission, and IoT gateway packet transmission are all included in the access layer. Here, a user filter only identifies appropriate background information while excluding duplicated data is required for feature control. It is worth noting that a significant number of sensors have several properties, but only a handful of these aspects are valuable in creating context data. However, the interface filter decreases energy and processor costs by reducing superfluous data exchange and increasing the speed of important data processing. Besides, the number of features varies depending on the program parameters and the type of data in the scope. On the other hand, context management is in charge of a server that saves data from the DB controller and the sync node, executes operations, and evaluates data values and thresholds. Here, several standard values (also known as marginal values) are initially assigned, followed by the currently agreed-upon values (data value). Moreover, duplicates aren't permitted on the server; therefore, only updated values are kept [26]-[28].

\subsubsection{Abstraction layer}

One of Openflow's most essential characteristics is the ability to link the digital layer to existing levels while keeping the structure in place. From a physical standpoint, the network is only a core device, yet it is feasible to continue service delivery (flow visors can be used). Here, a centralized system can track and regulate all types of traffic. This might improve bandwidth, robustness, mapping, and other factors, resulting in better service (QoS). In the multi-hop perspective, packets are relayed across specific nearby nodes. As a result, in a flow perspective, the nodes closest to the access point have a heavier load than the nodes further away, and the inactivation network of these critical nodes may collapse. Through access point dialogues between two sensor networks with a virtual link, the digital existence of nodes of sensors can address difficulties [26]-[28].

\subsubsection{Service layer}

Storage management encompasses all types of unknown and/or required data and technology that allows the model to be flexible and successful. It is in charge of both data storage and data privacy. Besides, it necessitates quick data access and integrates data using the resources available to improve business intelligence analysis and, most crucially, enhances processing. On the other hand, cloud computing infrastructure may assist all organizations, particularly small firms while solving entire IT difficulties for huge IT difficulties. This will benefit businesses, their employees, customers, and suppliers in areas where general business solutions may be provided. These incoming services must be interlinked and integrated to meet the demands of socio-economic aspects such as environmental evaluation, safety measures, climate strategic planning, agricultural modernization, and so on. By simplifying conscious smart agricultural services, the predicted context may be mapped out. This framework allows for the introduction of computers because of its diversity management. Consequently, it will, above all, keep the present network and cloud technologies up and operating [26]-[28].

\subsection{Framework for ICTization}

To construct a comprehensive ICT, a whole structure that can be reinforced nationally by ICT strategies and influencing variables for global harmonization must be successful. The layers' structural portion will reduce uncertainty by enhancing service, progress, and communications, as well as management and service integration. Beyond the anticipated model, our suggested technique is context aware and servicebased intelligent service. Here, the distribution, administration, and the root level of Figure 2. that is capable to maintain and manage the service integration. On the otherhand, Figure 3. simplified into three-tier servicebased frameworks, established a common interface between planned and received services is provided by these three levels. At the distribution level, definitions of operation and improvements are established, the decision support, authentication are the part of management level, and data analysis is concluded at the core level. The following are the functions of each layer [26]-[28]:

\subsubsection{Distribution layer}

The distribution layer is used to define entity's site and state that originates in our environment. Noted, the interaction between the user and the service requires information such as identification, locale, and location. This level has a lot of potential for providing new services, sharing resources, and improving the quality of services on an IoT network. In addition, it entails using virtualization to improve communication, network analysis, and operations, and it may provide a full IT solution to businesses. By changing the operating attitude and role switch status, a flexible system may be updated to automatically establish meaning. Moreover, it is vital to mention that our suggested smart agro system is one of the online services 
that are successful at this level; the information is delivered in a context shape that considers the user's situation and personality.

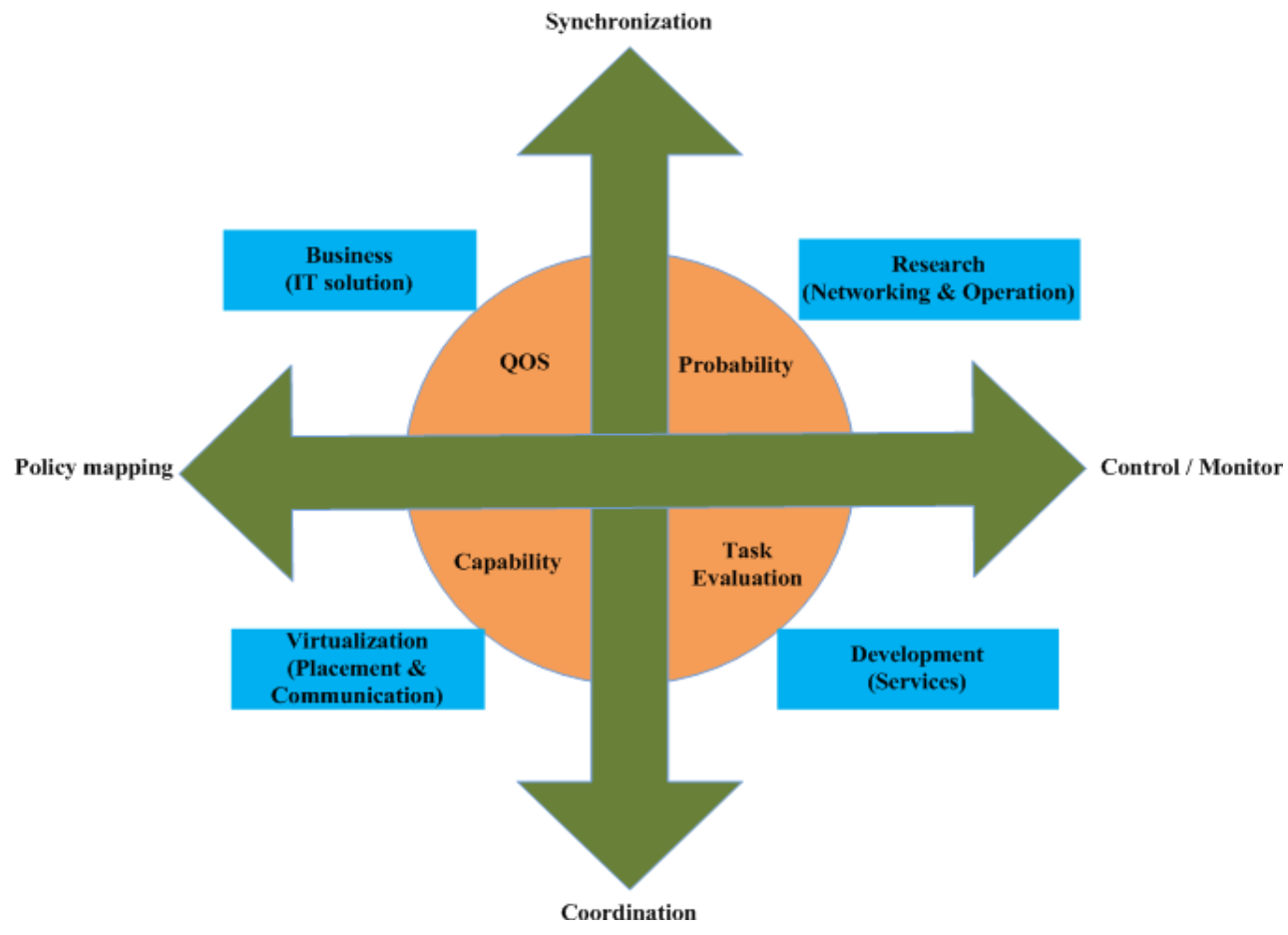

Figure 2. ICTization framework [28]

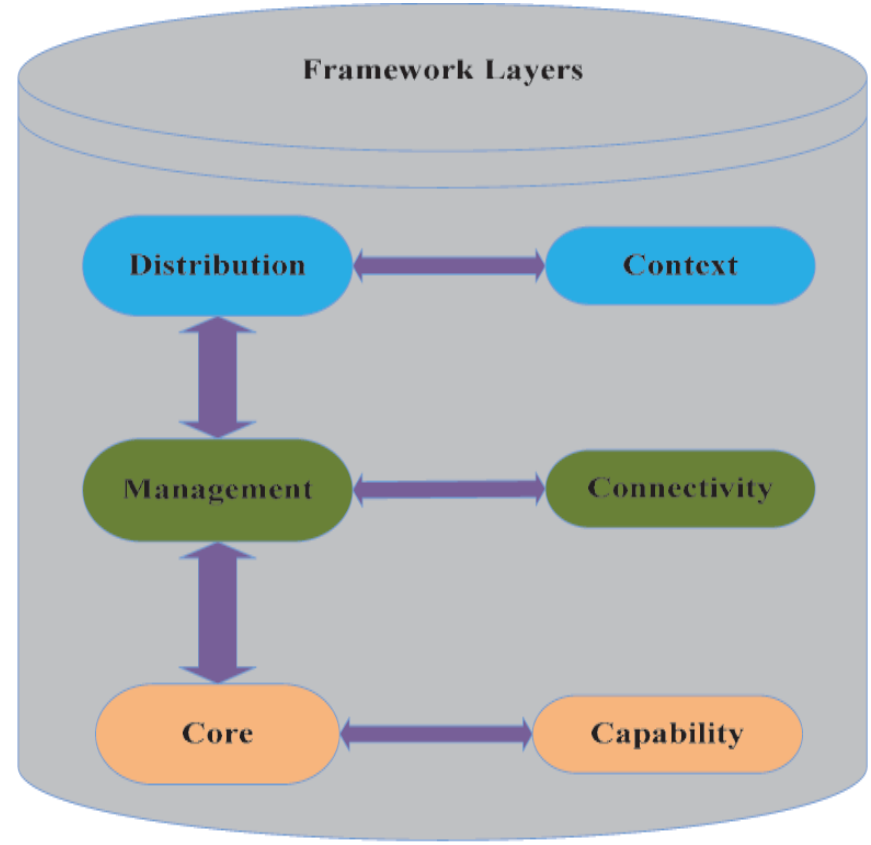

Figure 3. Framework layers for ICTization [28]

\subsubsection{Management layer}

This layer can manage connections and ensure that the intended service is available. From the standpoint of resources and consumers, it also involves coordination across several services for cost, power, 
time savings, and more. In this layer, the cost, flexibility and firms' over-IT problems may be handled and can be aided through affiliation or partnership. Corporations, their employees, consumers, distributors, and others will all benefit from it. Further, space and network management, rule analysis, scheduling, and operation planning are all part of this layer. As a consequence of the establishment of a new user interface, it integrates key services and logistical solutions, making it more convenient. These new services have been compelled to integrate and integrate to fulfil the demand for socio-economic concerns such as climate assessment, security calculations, climate control, agricultural modernization, and so on.

\subsubsection{Core layer}

At the bottom level, the core layer is in charge of decision-making and assessment. This level can be used to determine the likelihood of completing a job, including the likelihood of making a mistake. This layer contains the notion of aligning the basic and crucial technologies and data that will allow the structure to scale and function efficiently. Importantly, it is accountable not just for obtaining information, but also for ensuring privacy. This efficiently prevents data retrieval; connects information to service continuity; data analysis is dependent on critical services; and, most crucially, enhances space efficiency.

\section{RESULTS AND DISCUSSION}

Environment, IoT gateway, internet service provider, application server, service application, and user are the six elements depicted in Figures 4 and Figure 5. The following are the short functions of these entities:

- The environment refers to an agricultural field that is connected to IoT devices and may communicate data gathered by sensors via an IoT gateway.

- The IoT gateway is in charge of providing data to the application server as well as delivering emergency notifications about the crops field; these activities are necessary to connect the IoT gateway to the internet service provider through $3 \mathrm{G}$ or $4 \mathrm{G}$ network services.

- The internet service provider connects to mobile devices and keeps track of users' individuality.

- The application server is in charge of storing, processing and analysing data as well as managing user requests. This service application allows users to quickly get needed data from the application server.

- By converting user input to the application server, the application server will function as an interpreter. This program is responsible for informing the user and providing the requested information.

- Users who will receive information regarding crop health include farmers and agriculture officers. Based on the information obtained, the farmer can take appropriate action. An agriculture officer, on the other hand, will gather summary information from a database regarding the field.

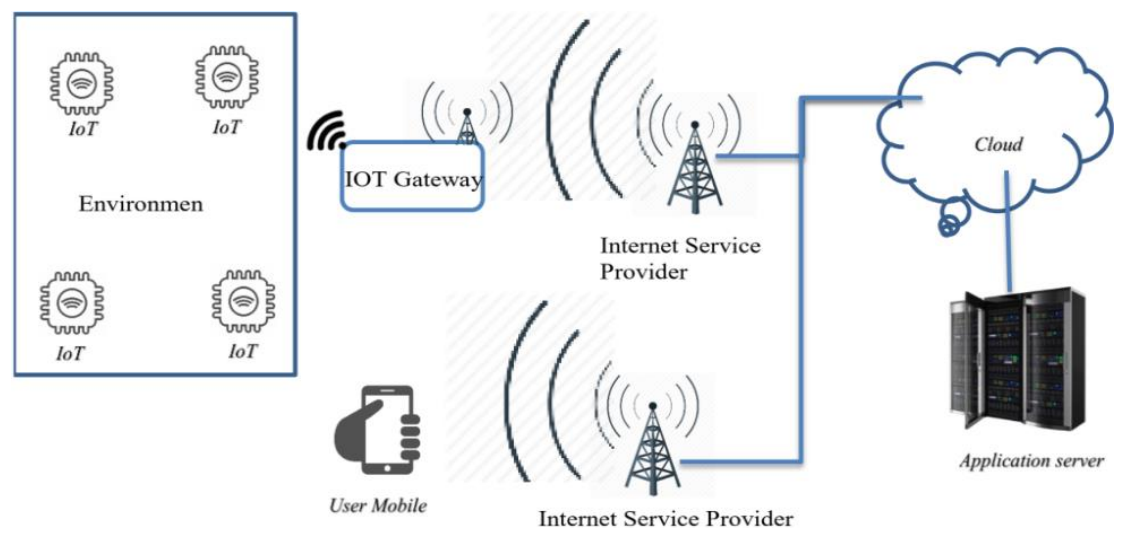

Figure 4. Network architecture

For example, if a farmer wishes to know the moisture content of his field soil, he may launch the service application and select to the check moisture option (Figure 6), which will request the current moisture measurement from the application server. On the other hand, IoT devices deliver sensor reading data, and the application server processes the raw data before providing it to the service application. If an unwelcome animal enters the agricultural field, the motion sensor will detect it and transmit a warning SMS via an IoT 
gateway, prompting the farmer to take fast action to protect the field. In any case, the smart Agro system is always in touch with its users as well as the crops field.

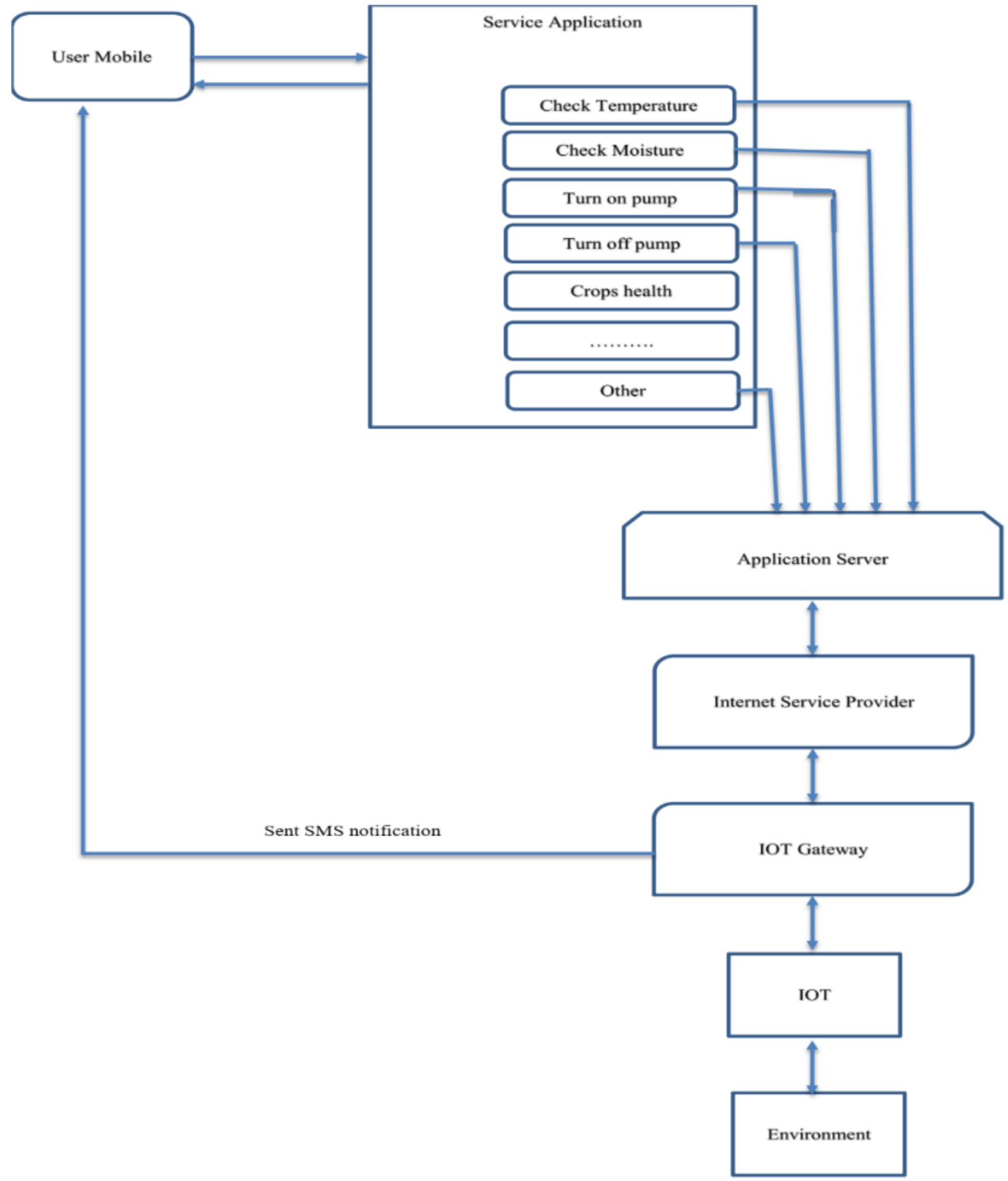

Figure 5. Smart agro system architecture 


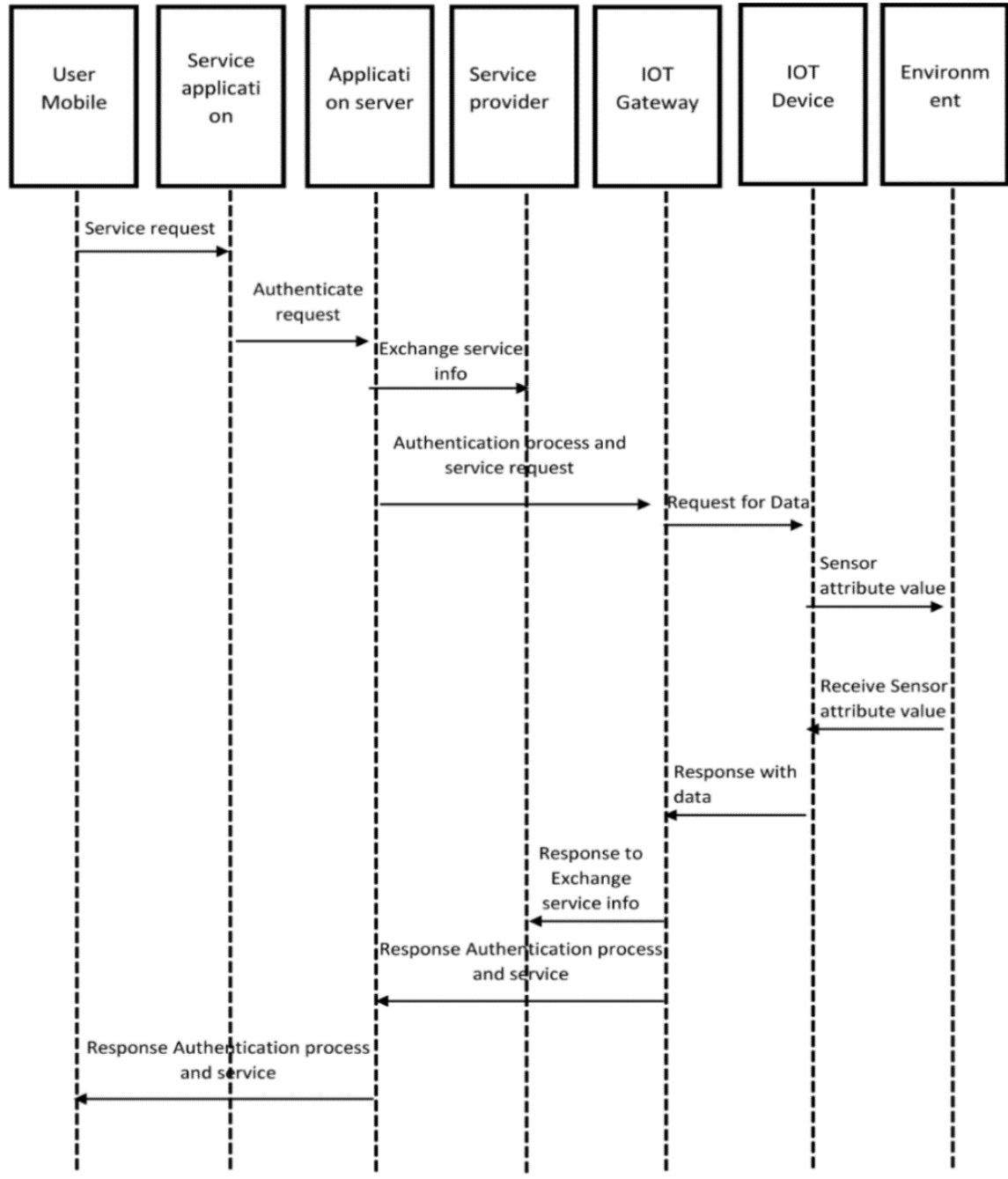

Figure 6. Operations of smart agro system

\section{CONCLUSION}

The recommended framework backed by the context may handle the e-services in addition to the raw data accepted by the physical device. The purpose of this framework is to coordinate, query, and control the individual entity's function. Besides, many sensors may be combined and transferred to their information context servers after being saved in the cloud using an IoT gateway. And, by combining management activities at many levels, it is possible to acquire contextual knowledge from the raw data in the region. Furthermore, this framework may be used to deploy a peripheral device across logical sections, domains, virtual network connections, and numerous applications without the need for a centralized coordination mechanism. Here, contextual awareness may play a key role in expanding the scope of e-services and technology by allowing for the perception of multiple meanings coming from the surrounding environment. Moreover, various manufacturers and system providers will benefit from clear IoT isolation and exact value in finishing their work and development on a wide scale.

In contrast, precision farming requires innovation and fresh information to enable an integrated and complete approach to technology. Using IoT devices, agriculture may become more efficient, dependable and may be used for a variety of agricultural applications. However, agriculture is Bangladesh's most important sector; nevertheless, farmers are losing interest in farming. Smart agriculture, on the other hand, through which farmers can simply manage their farming using a smartphone, is predicted to enhance interest in farming.

\section{ACKNOWLEDGEMENTS}

This work is funded by Daffodil International University. We would like to express our sincere gratitude and thanks to the university authority. 


\section{REFERENCES}

[1] S. Heble, A. Kumar, K. V. V. D. Prasad, S. Samirana, P. Rajalakshmi and U. B. Desai, "A low power IoT network for smart agriculture," IEEE 4th World Forum on Internet of Things (WF-IoT), 2018, pp. 609-614, doi: 10.1109/WF-IoT.2018.8355152.

[2] K. A. Patil and N. R. Kale, "A model for smart agriculture using IoT," International Conference on Global Trends in Signal Processing, Information Computing and Communication (ICGTSPICC), 2016, pp. 543-545, doi: 10.1109/ICGTSPICC.2016.7955360.

[3] E. P. R. da Fonseca, E. Caldeira, H. S. R. Filho, L. B. e Oliveiraa, A. C. M. Pereira and P. S. Vilela, "Agro 4.0: A data sciencebased information system for sustainable agroecosystem management," Simulation Modelling Practice and Theory, vol. 102, no. 102068, 2020, doi: 10.1016/j.simpat.2020.102068.

[4] V. Panwar, S. Mohanty and G. Anoop, "Agro-based micropore-structured ionic polymer sensor with enhanced ionic conduction and flexibility," Sensors and Actuators A: Physical, vol. 325, no. 11271, 2021, doi: 10.1016/j.sna.2021.112716.

[5] R. D. Harrison et al., "Agro-ecological options for fall armyworm (Spodoptera frugiperda JE Smith) management: Providing lowcost, smallholder friendly solutions to an invasive pest," Journal of Environmental Management, vol. 243, pp. 318-330, 2019, doi: 10.1016/j.jenvman.2019.05.011.

[6] R. Bendapudi, N. Kumbhar, P. Gaikwad and C. Lobo, “Agro-Met Services and Farmer Responsiveness to Advisories: Implicationsfor Climate Smart Agriculture,” Implications for Climate Smart Agriculture, pp 1-18, 2019, doi: 10.1007/978-3-319-71025-9 47-1.

[7] J. Jabin, A. M. Chowdhury, E. Tawsif Efaz, M. E. Adnan and M. Rezaul Islam, "An automated agricultural shading for crops with multiple controls," IEEE International IOT, Electronics and Mechatronics Conference (IEMTRONICS), 2020, pp. 1-7, doi: 10.1109/IEMTRONICS51293.2020.9216404.

[8] A. Ceglar, A. Toreti, M. Zampieri, V. Manstretta, T. Bettati and M. Bratu, "Clisagri: An R package for agro-climate services," Climate Services, vol. 20, no. 100197, 2020, doi: 10.1016/j.cliser.2020.100197.

[9] S. -L. Muraru, P. Condruz and I. Calciu, "Development of software for optimizing the fertilization of agricultural crop," 12th International Conference on Electronics, Computers and Artificial Intelligence (ECAI), 2020, pp. 1-6, doi: 10.1109/ECAI50035.2020.9223174.

[10] J. Z. Derakhshan, S. Firouzi and A. Kosari-Moghaddam, "Energy audit of tobacco production agro-system based on different farm size levels in northern Iran," Environ Dev Sustain, 2021, doi: 10.1007/s10668-021-01552-4.

[11] A. Sorokac and L. Rigali, "Industry 4.0 and Smart City in mobile machine's control systems," IFAC PapersOnLine, vol. 52, no. 27, pp. 473-476, 2019, doi: 10.1016/j.ifacol.2019.12.708.

[12] H. Meena, H. Nandanwar, D. Pahl and A. Chauhan, "IoT based perceptive monitoring and controlling an automated irrigation system," 11th International Conference on Computing, Communication and Networking Technologies (ICCCNT), 2020, pp. 1-6, doi: 10.1109/ICCCNT49239.2020.9225455.

[13] T. Ganokratanaa, P. Pramkeaw, M. Ketcham, N. Chumuang, W. Yimyam and P. Timted, "IoT System Design for Agro-Tourism," 18th International Joint Conference on Computer Science and Software Engineering (JCSSE), 2021, pp. 1-6, doi: 10.1109/JCSSE53117.2021.9493826.

[14] D. Devapal, "Smart Agro Farm Solar Powered Soil and Weather Monitoring System for Farmers, Materials Today," Materialstoday Proceedings, vol. 24, pp. 1843-1854, 2020, doi: 10.1016/j.matpr.2020.03.609

[15] E. Fabrizio et al., "Monitoring of a micro-smart grid: Power consumption data of some machineries of an agro-industrial test site," Data in Brief, vol. 10, pp. 564-568, 2017, doi: 10.1016/j.dib.2016.12.033.

[16] P. Sivalakshmi, K. G. Shanthi, K. Sangeethalakshmi, S. Sesha Vidhya, G. Sandhiya and M. Rajkumar, "Smart auction system flow model for Agro-Based sector farmers using block chain technology," Materialstoday Proceedings, 2021, doi: 10.1016/j.matpr.2021.05.634.

[17] A. Islam, K. Akter, N. J. Nipu, A. Das, M. Mahbubur Rahman and M. Rahman, "IoT Based Power Efficient Agro Field Monitoring and Irrigation Control System : An Empirical Implementation in Precision Agriculture," International Conference on Innovations in Science, Engineering and Technology (ICISET), 2018, pp. 372-377, doi: 10.1109/ICISET.2018.8745605.

[18] S. Ghosh, A. Sarkar, A. Mitra and A. Das, "Smart Cropping based on Predicted Solar Radiation using IoT and Machine Learning," IEEE International Conference on Advent Trends in Multidisciplinary Research and Innovation (ICATMRI), 2020, pp. 1-5, doi: 10.1109/ICATMRI51801.2020.9398323.

[19] L. A. Ibrahim, D. M. Aqil, and S. Azizah, "Feasibility of Internet of Things application for real-time healthcare for Malaysian pilgrims," Journal of Computational and Theoretical Nanoscience, vol. 16, no. 3, pp. 1169-1181, 2019.

[20] I. Ahmad and K. Pothuganti, "Smart Field Monitoring using ToxTrac: A Cyber-Physical System Approach in Agriculture," International Conference on Smart Electronics and Communication (ICOSEC), 2020, pp. 723-727, doi: 10.1109/ICOSEC49089.2020.9215282.

[21] R. K. Devi and M. Muthukannan, "An Internet of Things-based Economical Agricultural Integrated System for Farmers: A Review," 4th International Conference on Intelligent Computing and Control Systems (ICICCS), 2020, pp. 666-673, doi: 10.1109/ICICCS48265.2020.9121006

[22] R. Yusianto, Marimin, Suprihatin and H. Hardjomidjojo, "The Route Guidance System using Android-Based Navigation to Determine the Shortest Potatoes Distribution Route," International Seminar on Application for Technology of Information and Communication (iSemantic), 2020, pp. 320-326, doi: 10.1109/iSemantic50169.2020.9234244.

[23] M. Yaqot and B. C. Menezes, "Unmanned Aerial Vehicle (UAV) in Precision Agriculture: Business Information Technology Towards Farming as a Service," 1st International Conference on Emerging Smart Technologies and Applications (eSmarTA), 2021, pp. 1-7, doi: 10.1109/eSmarTA52612.2021.9515736.

[24] H. Durmus and E. O. Günes, "Integration of the Mobile Robot and Internet of Things to Collect Data from the Agricultural Fields," 8th International Conference on Agro-Geoinformatics (Agro-Geoinformatics), 2019, pp. 1-5, doi: 10.1109/AgroGeoinformatics.2019.8820578.

[25] A. R. Roselin and A. Jawahar, "Smart agro system using wireless sensor networks," International Conference on Intelligent Computing and Control Systems (ICICCS), 2017, pp. 400-403, doi: 10.1109/ICCONS.2017.8250751.

[26] A. Mahmud and A. Sattar, "ICTization Framework': A Conceptual Development Model through ICT Modernization in Bangladesh," International Conference on Advanced Computer Science Applications and Technologies, 2013, pp. 150-155, doi: 10.1109/ACSAT.2013.37.

[27] A. Mahmud and A. Sattar, "Deployment of Contextual Mobile Payment System: A prospective e-service based on ICTization framework from Bangladesh perspective," Proceedings of the International Conference on Advances in Computer Science and Electronics Engineering -- CSEE, pp. 86-92, 2014, doi: 10.15224/ 978-1-63248-000-2-48. 
[28] A. Mahmud and A. Sattar, "Deployment of contextual E-healthcare system: A prospective e-service based on context aware conceptual framework and ICTization framework model," IEEE 11th Conference on Industrial Electronics and Applications (ICIEA), 2016, pp. 77-82, doi: 10.1109/ICIEA.2016.7603555.

\section{BIOGRAPHIES OF AUTHORS}
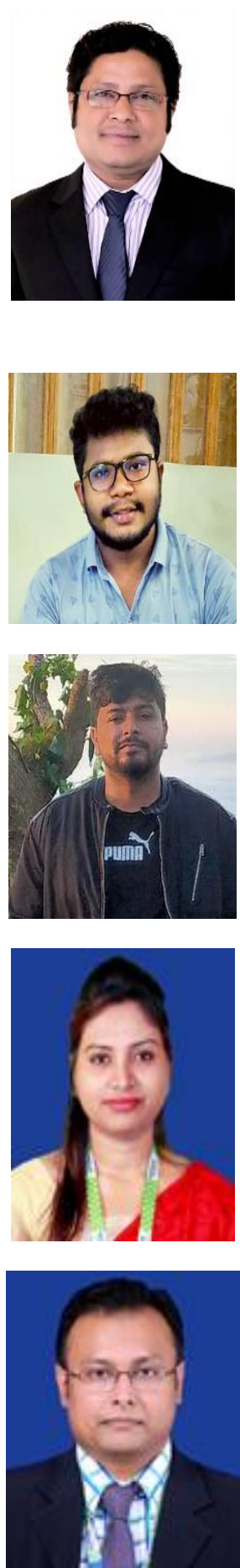

Abdus Sattar (iD 8I SC P was born in Comilla, Bangladesh, in 1983. Currently he is working as Assistant Professor at the Department of Computer Science and Engineering at Daffodil International University, Faculty of Science and Information Technology (FSIT). Previously, he was employed as Assistant Professor in the Department of Computer Science and Engineering (CSE) at Britannia University, Comilla. He is a PhD. Student at Bangladesh University Professionals, Bangladesh. He received Bachelor of Science in Computer Science and Engineering (CSE) from Ahsanullah University of Science and Technology (AUST), Bangladesh and Master's Program of Interactive Systems Engineering (ISE) from KTH-Royal Institute of Technology, Sweden. His research interests include machinne learning, iot, human computer interaction (HCI), and interaction design. He can be contacted at email: abdus.cse@diu.edu.bd.

Yeasin Arafat Shampod (iD 8 S SC P completed her BSc. in CSE at Daffodil International University, Bangladesh. His research interests include machine learning, augmented reality and IoT. He can be contacted at email: shampod15-6137@diu.edu.bd.

Md. Tanjid Ahmed (D) SC P s completed his MSc. and BSc. in CSE at Daffodil International University, Bangladesh. His research interests include IoT and machine learning. He can be contacted at email: tanjid2217@diu.edu.bd.

Nasrin Akter (DD ISI SC P currently she is working as Lecturer at the Department of Computer Science and Engineering at Daffodil International University, Faculty of Science and Information Technology (FSIT). She completed her MSc. and BSc. in CSE at Daffodil International University, Bangladesh. Her research interests include big data analytics and cyber security. She can be contacted at email: nasrin.cse@diu.edu.bd.

Arif Mahmud (D) If SC P is continuing his Ph.D. degree in Universiti Sains Malaysia, He obtained his M. Sc from Mid Sweden University, Sweden and B.Sc. degree in Computer Science and Engineering from Americal International University (AIUB), Bangladesh. Now he is an Assistant Professor at the Department of Computer Science and Engineering in Daffodil International University. He is much fond of research. He has had a number of publications in international journals and conference proceedings. He has worked as a reviewer of a number of international journals and conferences. His main research interest is in computer networks, network security. He can be contacted at email: arif.cse@diu.edu.bd. 